\title{
REFLEXIONES SOBRE FILOSOFÍA MORAL
}

Tenemos el enorme agrado de presentar el número 20\# de nuestra publicación con el que Revista Prometeica alcanza sus primeros diez años desde su inicio en 2010. Alcanzar esta marca en la continuidad en nuestro trabajo editorial nos lleva sin duda a reflexionar sobre las diferentes iniciativas académicas que la revista ha podido vehiculizar, a la vez que el trabajo de difusión que nos proponemos de diferentes áreas de investigación, así como la posibilidad de establecer un espacio de diálogo entre diferentes disciplinas del ámbito universitario.

En este sentido, el número 20\# será también el 6to número temático publicado en Revista Prometeica. En esta oportunidad, dedicado al pensamiento Alasdair MacIntyre, un autor contemporáneo de gran relevancia en el marco de la tradición aristotélico-tomista, y en particular en los debates sobre ética y filosofía moral. Los trabajos que componen el número buscan reflexionar sobre diferentes aspectos, no solo de la obra de MacIntyre desde una perspectiva general, sino fundamentalmente focalizados en los debates que surgen a partir de su libro: Ethics in the Conflicts of Modernity. An Essay on Desire, Practical Reasoning and Narrative, publicado en 2016.

La propuesta de realizar este número temático y el inicio del trabajo editorial en este sentido comenzó a mediados de 2018 cuando el Dr. J. Maximiliano Loria nos propuso realizar un número dedicado pensamiento macintaryano convocando a diferentes especialistas destacados en la interpretación y el debate de sus ideas. En este sentido, el aporte del Dr. Loria ha sido fundamental desde el inicio de la planificación del número, pues nos ha posibilitado contar con colaboraciones de investigadores de diferentes universidades y nacionalidades que permiten reconstruir un panorama en la interpretación actual de la obra macintaryana en el plano internacional. La participación de investigadores de España, Chile, Colombia, Argentina, Hungría y Estados Unidos, permitirá reunir para el lector, diferentes enfoques y perspectivas de apropiación del texto de MacIntyre desde una aproximación que pone el énfasis en la dimensión moral y propositiva de su pensamiento.

A su vez, el número cuenta con una entrevista a Caleb Bernacchio, en la que se recorre su aproximación al autor y el horizonte de problemas que observa en su pensamiento. Y una la reseña al libro Aproximación al pensamiento de Alasdair MacIntyre, de Juan Martín Fernández publicado en 2018.

Esperamos que el número contribuya a enriquecer el debate sobre filosofía moral y para incorporarse a la reflexión ética desde la perspectiva de uno de los autores más relevantes de la actualidad.

Emiliano Aldegani

(Universidad Nacional de Mar del Plata; CONICET)

emilianoaldegani@gmail.com 